\section{The Annotated Darwin}

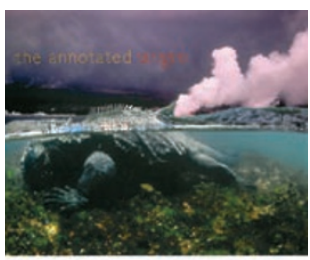

\section{The Annotated Origin: A Facsimile of the First Edition of On the Origin of Species}

By Charles Darwin.

Annotated by James T. Costa

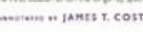

The Belknap Press of Harvard University Press,

2009, 576 pp. Price: $£ 25.95$

\section{Reviewed by David H. A. Fitch}

Who has not found joy, surprise, and intellectual ferment upon reading a book with "The Annotated..." in the title? The Annotated Mother Goose, The Annotated Alice, The Annotated Sherlock Holmes, and even The Annotated Grateful Dead Lyrics project provide breadth and depth that only serve to expand our experience, understanding and appreciation of works we thought we knew so well. Professor James Costa of Western Carolina University has now provided us with The Annotated Origin, a masterful, refreshing, thoroughly enjoyable and sometimes novel perspective on Charles Darwin's On the Origin of Species.

Like Costa, I too was inspired by Stephen Jay Gould to incorporate On the Origin of Species into the teaching of my undergraduate evolution course, along with an online resource of notes to help students navigate through the heaving sea of Victorian prose. However, Costa has ventured far beyond merely providing such explanatory guideposts. With copious notes placed in the large margins of a beautiful facsimile of the first edition, Costa provides an eclectic but extraordinarily useful and insightful series of crossreferences, natural history trivia, updates, expansions and comparisons to modern data, historical context, methodology, philosophy and biographical details. This book is no mere coffee-table showpiece. Along with Peckham's 1959 Variorum and recent online resources of Darwin's correspondence and other writings, this lovingly created work must be rated as one of the most important resources available for Darwin scholarship and education.

Costa is well-justified to use the first edition for this odyssey. For more than a decade following the first edition, Darwin obsessively edited his masterwork to pacify or rebut criticism. As a result, the sixth and last edition was a third longer than the first, is fretted with extra circumspection and is more difficult to follow in places. The first edition, in contrast, retains a freshness and directness, and represents the founding moment of the Darwinian revolution itself.

An introduction by Costa provides an insightful background into two different aspects leading to On the Origin of Species. First, Costa leads us through a brief history of Darwin's experiences and the evolution of his thinking prior to the publication of the first edition. We see how Darwin's original adherence to natural theology was altered by his keen skills of

David H. A. Fitch is in the Department of Biology, New York University, 100 Washington Square East, New York, New York, USA.

e-mail:df3@nyu.edu observation and capacity for critical analysis. We see how important the interactions were that Darwin had with others (Costa exploits the wealth of Darwin's correspondences throughout the book). And we see how Darwin's book itself emerged and was forever altered by the precipitative receipt of Wallace's manuscript, which proposed similar ideas, in the summer of 1858. Second, Costa provides an interesting overview of On the Origin of Species' logical structure. Darwin apparently used Sir John Herschel's tripartite philosophical scheme to demonstrate natural selection as the 'true cause' of evolution; that is, the mechanism exists, it is sufficient to produce such change and it serves to broadly explain diverse phenomena.

The 900 or so annotations are not miniscule footnotes, but easily legible text placed adjacent to the facsimile text. Some annotations deal with the unreferenced citations that Darwin interspersed at many points. Because Darwin intended On the Origin of Species to be only an abstract (of another abstract), he purposely left out full references to authorities of his "many facts", as currently practiced for many textbooks and popular works. Costa has not only provided many of these references, but has also added particular details of interest. For example, he provides the actual translation of Pliny the Elder that Darwin would have read regarding the importance that ancient Romans placed on cultivating pigeon breeds (Darwin's 'model system' for many of his experiments and observations were domesticated pigeon breeds). Many annotations provide precise cross-references to Darwin's other works or to correspondence, a great aid to scholarship.

Some annotations explain the references to what could be otherwise cryptic botanical and zoological species or varieties, such as teasels, Lepidosiren, Ornithorhynchus, the King Charles spaniel, Ulex, furze, batrachians, suctorial crustaceans, and of course cirripedes (barnacles, another great model system for Darwin). Some annotations explore his experiments more fully (for example, concerning the dispersal of freshwater molluscs). There are expansions (for example, about pigeons, even so far as providing the recipe Darwin used for preserving their skeletons) and very helpful explanations (for example, about what Darwin meant by the mechanism of natural selection, and what it can and cannot do).

There are a significant number of historical notes, some explicitly providing a context in which to appreciate the enormous significance of Darwin's findings. For example, Darwin not only revolutionized systematics and embryology, but also provided a mechanistic explanation for homology. Costa provides some wonderful history about the homology concept, which plays out through several pages of annotations. Actually, this last example brings up one unfortunate result of using the annotation style: successive annotations are often disjunct, and it can be difficult to follow a continuous train of thought. But for that, the reader should of course turn to Darwin's text.

Costa has also written a succinct "Coda" at the end, which provides a succinct history of On the Origin of Species' own evolution through its multiple revisions and editions. For example, we learn that Darwin did not incorporate Herbert Spencer's unfortunate phrase "survival of the fittest" until the fifth edition. More significant than such trivia, Costa leads us through the most important criticisms Darwin experienced, and his responses to them. As if this were not enough, Costa adds an entire section of biographical data on people mentioned in the book. Who could ask for more?

The author declares no competing financial interests. 